\title{
Utility Of Three-Dimensional Heads-Up Surgery In Cataract And Minimally Invasive Glaucoma Surgeries
}

This article was published in the following Dove Press journal: Clinical Ophthalmology

\author{
Hisato Ohno (D) \\ Ohno Eye Clinic, Asaka, Saitama, Japan
}

Correspondence: Hisato Ohno

Ohno Eye Clinic, 2-I4-I8 Nishihara,

Asaka, Saitama 35I-0034, Japan

Tel +8I 484243733

Fax +8I 48424 557।

Email vitrectman@ohno-eye.com
Purpose: This study aimed to assess the utility of the three-dimensional (3D) heads-up visualization system for minimal incision cataract surgery (MICS) and minimally invasive glaucoma surgeries (MIGSs).

Methods: Toric intraocular lens (IOL) implantation with phacoemulsification and trabecular microbypass stent implantation in patients with cataract and open-angle glaucoma were performed using the heads-up 3D visualization system combined with surgical navigation rather than the conventional microscope.

Results: This procedure was found to have the following advantages: the ability to clearly observe the anterior chamber angle image without requiring frequent focus adjustment owing to the extended depth of field and emphasized stereoscopic effect provided by this system and maintain the surgeon's posture.

Conclusion: The feasibility and comfort of this system are greater than those of the conventional microscopic for performing MICS and MIGS.

Keywords: toric intraocular lens, phacoemulsification, open-angle glaucoma

\section{Introduction}

Recently, the method of conducting surgery using the three-dimensional (3D) heads-up visualization system, known as the heads-up surgery (HUS), has been widely accepted, especially for vitreoretinal procedures. Using digitally assisted image manipulation on the display, HUS can be comfortably performed even under conditions such as low-intensity light and extended depth of field at high magnification. ${ }^{1-3}$ In addition, multiple data, such as intraoperative optical coherence tomography and operative field view data, can be simultaneously observed on the display. Consequently, we determined that surgical navigation combined with a 3D heads-up display is the most practical tool for performing minimal incision cataract surgery (MICS) in clinical settings. ${ }^{4,5}$

Moreover, to ensure a good view of the trabecular meshwork in minimally invasive glaucoma surgery (MIGS), ${ }^{6,7}$ a gonioprism is used to inspect the angle. However, the surgeon must have certain experience and skill to achieve such a view. Based on this, we can consider that the extended depth of field at high magnification obtained in HUS is preferable for angle inspection using gonioprism. In this study, we reported the feasibility of HUS for MICS and MIGS. 


\section{Patients And Methods}

Toric intraocular lens (IOL) implantations with phacoemulsification and trabecular microbypass stent implantation (iStent; Glaukos, CA, USA), which is an MIGS, using the NGENUITY 3D Visualization System with VERION Image Guided System (Alcon, Fort Worth, TX, USA) combined with the Leica Proveo 8 microscope (Leica Microsystems, Wetzlar, Germany) were performed for patients with cataract and open-angle glaucoma. This implantation was guided by VERION to achieve precise positioning (Figure 1). Furthermore, the Ocular Hill Surgical Gonioprism (Ocular Instruments Inc, Washington, USA) was used to implant iStent in a conventional manner, in which the microscope and patient's face are tilted to achieve a good view of the anterior chamber angle. In addition, because the 3D display was placed in front of the surgeon, the surgeon's posture was maintained throughout the procedure (Figure 2, Video S1).

Video S1 shows toric intraocular lens (IOL) implantations with phacoemulsification and trabecular microbypass stent implantation, using the NGENUITY 3D

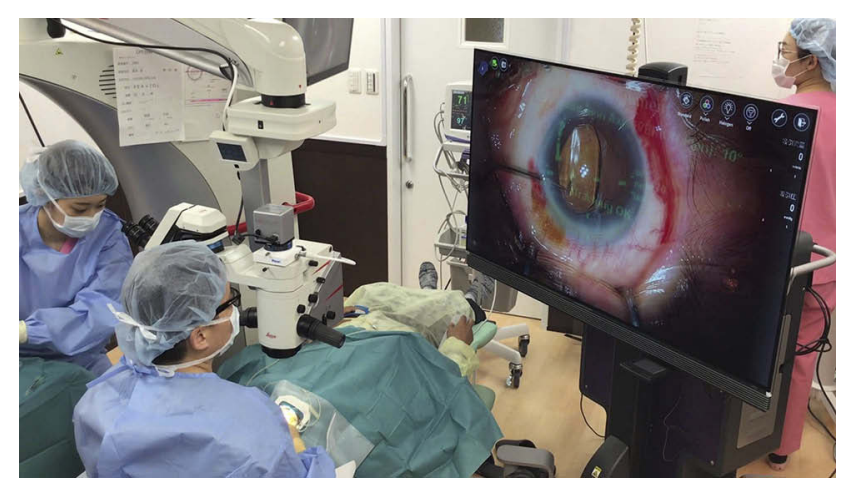

Figure I Toric IOL implantation by NGENUITY 3D Visualization System combined with VERION image guided system.

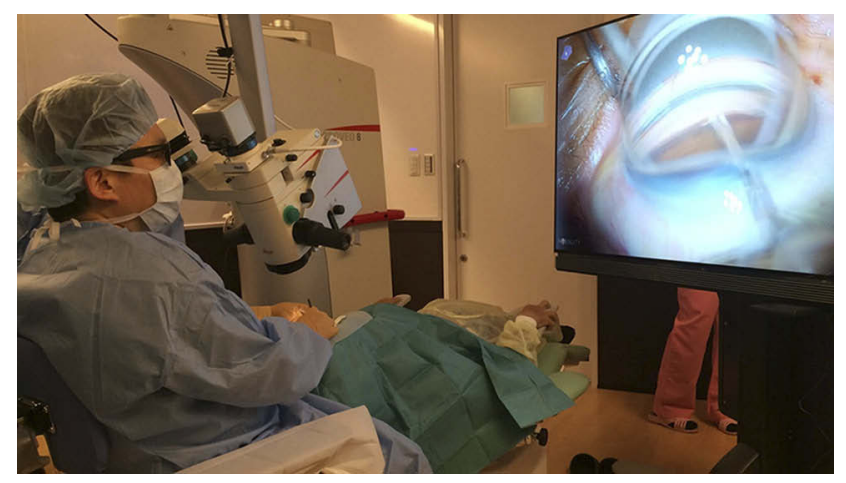

Figure 2 In HUS, the surgeon's posture is maintained even if the microscope and patient's face are tilted to acquire a good view of the anterior chamber angle when using a gonioprism.
Visualization System with VERION Image Guided System for a patient with cataract and open-angle glaucoma. The surgeon's posture is maintained during surgery.

\section{Results}

Compared with the conventional microscopic surgery, cataract surgery and trabecular microbypass stent implantations were compatible with HUS combined with Verion image guided system. Moreover, because of the extended depth of field at high magnification and emphasized stereoscopic effect provided by this technique, frequent focus adjustment is not required for trabecular microbypass stent implantation, unlike that required when using the conventional microscope.

\section{Discussion}

With HUS, it is possible to process the original image on the display exactly according to the surgeon's requests without compromising image quality. There are several advantages of HUS such as lower intensity of light source, exaggeration of the structure and color of the image, overlay the images, and picture in picture (several images on the display simultaneously). So far, most reports of HUS are related to vitreoretinal surgery. ${ }^{1-3}$ However, with all these factors considered, the feasibility of this procedure is not only for vitreoretinal surgery but also for other kinds of ophthalmic surgeries. In this study, we report the feasibility of MICS and MIGS via 3D platforms that offer good visualization (less need for focusing and emphasized stereoscopic effect by larger display), good compatibility with Verion image guided system, and surgeon's comfort. HUS was never inferior to the conventional microscopic surgery in MICS and MIGS. However, we believe that HUS might have the potential to change surgical microscopic observation system drastically. Further studies and innovation are required to develop the conventional microscopic observation system.

\section{Abbreviations}

HUS, Heads-up surgery; IOL, Intraocular lens; MICS, minimal incision cataract surgery; MIGS, minimally invasive glaucoma surgeries.

\section{Acknowledgment}

The author would like to thank Enago for the English language review. 


\section{Disclosure}

The author reports no conflicts of interest in this work.

\section{References}

1. Eckardt C, Paulo EB. Heads-up surgery for vitreoretinal procedures: an experimental and clinical study. Retina. 2016;36(1):137-147. doi:10.1097/IAE.0000000000000689

2. Adams MK, Thornton S, Regillo CD, Park C, Ho AC, Hsu J. Minimal endoillumination levels and display luminous emittance during threedimensional heads-up vitreoretinal surgery. Retina. 2017;37(9):17461749. doi:10.1097/IAE.0000000000001420

3. Freeman WR, Chen KC, Ho J, et al. Resolution, depth of field, and physician satisfaction during digitally assisted vitreoretinal surgery. Retina. 2019;39:1768-1771. doi:10.1097/IAE.0000000000002236
4. Webers VSC, Bauer NJC, Visser N, Berendschot TT, van Den Biggelaar FJ, Nuijts RM. Image-guided system versus manual marking for toric intraocular lens alignment in cataract surgery. J Cataract Refract Surg. 2017;43(6):781-788. doi:10.1016/j.jcrs.2017.03.041

5. Weinstock RJ, Diakonis VF, Schwartz AJ, Weinstock AJ. Heads-up cataract surgery: complication rates, surgical duration, and comparison with traditional microscopes. J Refract Surg. 2019;35(5):318-322. doi:10.3928/1081597X-20190410-02

6. Samuelson TW, Katz LJ, Wells JM, Duh YJ, Giamporcaro JE; US iStent Study Group. Randomized evaluation of the trabecular micro-bypass stent with phacoemulsification in patients with glaucoma or cataract. Ophthalmology. 2011;118:459-467. doi:10.1016/j.ophtha.2010.07.007

7. Neuhann TH. Trabecular micro-bypass stent implantation during smallincision cataract surgery for open-angle glaucoma or ocular hypertension: long-term results. J Cataract Refract Surg. 2015;41:2664-2671. doi:10.1016/j.jcrs.2015.06.032
Clinical Ophthalmology

\section{Publish your work in this journal}

Clinical Ophthalmology is an international, peer-reviewed journal covering all subspecialties within ophthalmology. Key topics include: Optometry; Visual science; Pharmacology and drug therapy in eye diseases; Basic Sciences; Primary and Secondary eye care; Patient Safety and Quality of Care Improvements. This journal is indexed on PubMed

Submit your manuscript here: https://www.dovepress.com/clinical-ophthalmology-journal
Dovepress

Central and CAS, and is the official journal of The Society of Clinical Ophthalmology (SCO). The manuscript management system is completely online and includes a very quick and fair peer-review system, which is all easy to use. Visit http://www.dovepress.com/ testimonials.php to read real quotes from published authors. 